\title{
Margin Requirements and Systemic Liquidity Risk
}

\begin{abstract}
We develop a model in which margin procyclicality and the propensity for liquidity hoarding interact to generate a systemic liquidity crisis. In this model, banks lend and borrow in the interbank market to mitigate liquidity risk and trade derivatives contracts in the OTC derivatives market to mitigate market risk. The daily mark-to-market of derivatives contracts results in daily margin calls that banks cover using high quality liquid assets. We find that distress due to margin procyclicality in the derivatives market can spillover to the interbank market leading to systemic liquidity risk. Interconnectedness further amplifies the effects of systemic risk within the interbank market. The model shows that central clearing might increase the possibility of systemic liquidity risk due to tight margin requirements and the timing of cash flows required from banks. We also find that haircut levels affect the possibility of systemic liquidity risk, and highlight the potential role of a market maker of last resort in limiting this possibility.
\end{abstract}

Keywords: Margin Procyclicality, Funding Liquidity Risk, Systemic Risk, Contagion, Networks, Agent-Based Modelling.

JEL Classification: G01, G15, G21, G28. 


\section{Introduction}

The financial crisis of 2008 has highlighted the threats of interconnectedness to the stability of the financial system. In the aftermath of this crisis, central clearing of all standardized derivatives contracts has been enacted to reduce interconnectedness in overthe-counter (OTC) derivatives markets (Yellen, 2013). ${ }^{1}$ In addition, the Bank for International Settlements (BIS) has issued similar margin requirements for non-centrally cleared derivatives (BIS-IOSCO, 2013, 2015). As a result, the OTC market participants are now required to make margin payments at least daily in response to changes in the market value of their derivatives contracts.

In this paper, we analyse the impact of margin requirements on funding liquidity risk of the OTC derivatives market participants. Previous work has focused on counterparty credit risk as in Acharya and Bisin (2014) who show that centralized clearing mechanisms provides transparency of trade positions which eliminates counterparty risk externality, and Loon and Zhong (2014) who suggest that introducing central clearing in the CDS market lowers counterparty credit risk and improves post-trade transparency and trading activity. In contrast, we consider the overlooked impact of margin requirements on funding liquidity risk of market participants. In particular, we consider margin procyclicality during times of high market volatility as a side effect of tight margin requirements. We focus on a specific question that has recently risen to the top of policy agendas: how does margin procyclicality in conjunction with propensity for liquidity hoarding affect the systemic risk propagation in the financial network of the interbank market?

The impact of margin requirements on funding liquidity risk is a key concern for policy-making. On the one hand, variation margin which is required to be posted daily is significant compared to initial margin which is required only at the inception of a contract. According to the International Swaps and Derivatives Association (ISDA), at the end of first quarter of 2017, the initial margin and variation margin posted by derivatives dealers are estimated at $\$ 280.5$ billion and $\$ 1131.2$ billion, receptively (ISDA, 2017). On

\footnotetext{
${ }^{1}$ The Dodd-Frank Wall Street Reform and Consumer Protection Act of 2010 in the US and the European Market Infrastructure Regulation of 2012 in Europe both mandate central clearing of certain standardized and eligible OTC derivatives.
} 
the other hand, margin requirements focus on reducing counterparty credit risk through the mandate of daily mark-to-market and tight credit support annexes (CSA). Given that the amounts of variation margin calls can be large, there is significant liquidity risk from tight CSAs.

We develop a model that considers the impact of margin procyclicality on funding liquidity risk in the spirit of the seminal work of Brunnermeier and Pedersen (2009) who model the interaction between market liquidity and funding liquidity in centralized markets. They show that, under certain conditions, interbank haircuts are destabilising and market liquidity and funding liquidity are mutually reinforcing, leading to liquidity spirals. In the same vein, the ability of market participants in our model to meet margin requirements depends on their availability of funding. In our model, counterparty credit risk is mitigated by requiring banks to post daily cash margins to reduce exposure at default. If counterparties do not have sufficient cash to meet a margin call, they become distressed.

Our model considers bank behavior in both the OTC derivatives and the interbank markets. As in Faulkender (2005), we assume that banks trade in the OTC derivatives market for both hedging and speculation purposes. We also consider herding behavior in the interbank market as a driver of contagion similar to Acharya and Yorulmazer (2008). They show that banks engage in herding behavior in order to minimize the effect of bad information about other banks on their own borrowing costs while obtaining funding from depositors. In our model, banks engage in herding behavior while they raise liquidity and they have to decide between withdrawing their lending to other banks in the interbank market and using their less liquid assets as collateral to obtain funding.

Our model is populated with heterogeneous banks with varying features of size, balance sheet compositions, market risk exposures, and risk aversion. Banks trade derivatives contracts with each other in order to manage their exposures to market risk. A bank selects the direction of a derivatives contract based on its own risk aversion and idiosyncratic market risk exposure. For ease of exposition, we focus on the case of two types of banks with respect to risk aversion. The first is high risk-averse banks which 
aim to hedge their idiosyncratic market risk exposures and maintain net fixed interest rate exposure. The second is low risk-averse banks which speculate on market interest rate movements and accept to have net variable interest rate exposures.

We also show how the theory of multilayer networks can be used to analyze the spillover of distress from one segment of the financial market (OTC derivatives) to another one (interbank). In particular, we represent the OTC derivatives and interbank markets as two directed networks, where some banks participate in both networks while others participate in only one out of the two networks. We quantify the credit exposures that result from banks' derivatives positions in a network setting. These exposures change with changes in the market interest rates which leads to margin calls in order to reduce exposures at default. We then use this model to investigate some of the policy implications of margin requirements. To this end, the general approach followed is to perturb the OTC derivatives market with an interest rate shock and analyse the dynamics of contagion and systemic risk within the interbank market.

We find that margin procyclicality can lead to the onset of a systemic liquidity crisis within the interbank market. Furthermore, Our model highlights the mechanism by which margin procyclicality can induce liquidity hoarding contagion in the interbank market. When a financially distressed bank refuses to rollover its current overnight lending to other institutions in the interbank market, it effectively transfers its distress to those institutions. As more institutions decide to hoard liquidity, a systemic liquidity crisis propagates within the interbank market. The model also shows that contagion can arise endogenously due to banks' propensity for hoarding liquidity during distress times. This contagion dynamic is thus characterized by a self fulfilling process among banks.

We also use the model to explore the impact of other factors on distress spillover and systemic liquidity risk. For instance, we show that central clearing might in fact increase the possibility of a systemic liquidity crisis due to tight margin requirements and the timing of cash flows required from banks. Also, consistent with previous evidence, the model predicts that interconnectedness amplifies the effect of systemic risk within the interbank market. Furthermore, the model shows that haircut levels affect the possibility 
of a systemic liquidity crisis, and highlights the potential role of a market maker of last resort in limiting this possibility. Finally, the results of our model illustrate the tension between the micro-level decisions of individual banks about their interbank lending and the macro-level outcomes of these decisions in the form of systemic loss that results from the cost of withdrawing interbank loans.

The rest of this paper proceeds as follows. Section 2 provides an overview of related literature. Section 3 presents the market setup. Section 4 provides a model to analyse contagion and systemic risk due to margin procyclicality. Section 5 provides an overview of the model calibration and validation. Section 6 presents the results. Section 7 concludes the paper.

\section{Related Literature}

Assessing the impact of the central clearing mandate and subsequent margin requirements on the OTC derivatives market has brought about much debate among academics, market participants and policy makers alike. Much of the discussions have involved the impact on collateral demand with a focus on the trade-off between the benefits of multilateral netting within a class of contracts against lost bilateral netting benefits across different classes. Duffie and Zhu (2011) are among the first studies to explore this tradeoff. Their analytical framework highlights the role of the market network structure and netting arrangements in determining the change in collateral demand. Another strand of research has focused on counterparty credit risk. For instance, Acharya and Bisin (2014) shows that centralized clearing mechanisms provide transparency of trade positions which eliminates counterparty risk externality. Similarly, Loon and Zhong (2014) suggest that introducing central clearing in the CDS market lowers counterparty credit risk and improves post-trade transparency and trading activity. In contrast with previous work, we focus on the critical impact of margin requirements on funding liquidity risk. An impact that arises due to margin procyclicality which occurs when margin requirements rise at times of market stress, leading to even more stress.

Our paper contributes to the growing body of literature on financial contagion and systemic risk. We adopt a balance sheet approach similar to what is followed in the 
strand of literature on contagion that focuses on default cascades due to direct credit interlinkages among banks and solve for equilibrium as a fixed point mapping (see e.g. Eisenberg and Noe, 2001; Furfine, 2003; Freixas et al., 2000; Allen and Gale, 2000). We deviate, however, from this strand of literature in that we do not attempt to model cascade defaults due to payments shortage. Instead, we attempt to model distress cascades due to funding runs. Yet, another strand of literature use a similar balance sheet setting to model common asset holdings as a transmission mechanism for contagion (see e.g. Cifuentes et al., 2005; Krishnamurthy, 2010; Shleifer and Vishny, 2011; Caccioli et al., 2015).

Liquidity hoarding is one of the main channels through which financial contagion spreads. We contribute to this literature by developing a model that illustrates liquidity hoarding due to margin procyclicality. Our work is closely related to the model of Gai et al. (2011) in which liquidity hoarding in the interbank market arises due to exogenous shocks to haircuts. We extend their framework to study the impact of margin procyclicality on funding liquidity risk and analyse its potential role in originating liquidity hoarding contagion in the interbank market. Similarly, Acharya and Skeie (2011) suggest that a bank's propensity to hoard liquidity in the interbank market is a function of its own rollover risk. The same notion is extended more in Acharya et al. (2011) whose model provides a micro-foundation for the funding risk of financial institutions with an extreme maturity mismatch between assets and liabilities. Anand et al. (2012) study bad news propagation within the interbank market and show how funding maturity and network structure interact to generate systemic financial crises. Brossard and Saroyan (2016) show that banks liquidity influences the overnight rates in the interbank market and show that this is probably explained by hoarding and short-squeezing behaviors.

Another group of studies on liquidity hoarding uses information-theoretic models that combine liquidity shortages and Knightian uncertainty (Knight, 1921) to study flight to quality episodes Caballero and Krishnamurthy (2008). Similarly, Bolton et al. (2011) provide a model to determine the equilibrium mix of banks cash reserves and liquidity obtained through sales of assets. Allen et al. (2009) show that it might be constrained efficient for banks to hoard liquidity if there is an increase in aggregate uncertainty about aggregate liquidity demand compared to idiosyncratic liquidity demand. Battiston et al. 
(2012) highlight the role of connectivity in systemic risk propagation and show that a financial network is resilient to shocks to a specific limit, beyond which the network connectivity might exacerbate the systemic risk propagation. Diamond and Rajan (2011) show that banks might become illiquidity seekers to avoid realized losses due to asset fire sales and in anticipation of asset price recoveries. Eross et al. (2016) find evidence of endogenous responses and spillovers within the interbank market. Lopez-Espinosa et al. (2013) examine the impact of bank-specific factors on its solvency risk and show that funding risk is the main driver of systemic risk.

Our paper contributes also to the literature on procyclicality. One of the earliest models in this area is by Grossman and Miller (1988) which determines an equilibrium level of market liquidity based on the supply and demand for immediacy. In the same spirit, the seminal work of Brunnermeier and Pedersen (2009) links market liquidity and funding liquidity and shows that both margin spirals and losses spirals might result endogenously due to procyclicality. Our paper is also related to studies on margin procyclicality (see e.g. Murphy et al., 2014, 2016) and price procyclicality (see e.g. Danielsson et al., 2012; Danielsson and Zigrand, 2008). Another strand of models on procyclicality focuses on the link between leverage and market volatility. While some models focus on the endogenous determination of leverage when assets are used as collateral (see e.g. Geanakoplos, 2010; Fostel and Geanakoplos, 2012; Geanakoplos and Pedersen, 2012; Aymanns and Farmer, 2015), others focus instead on the impact of procyclical leverage on systemic risk (see e.g. Gorton, 2010; Gorton and Metrick, 2012; Tasca and Battiston, 2016).

Our paper contributes also to the strand of literature that suggests that banks behavior play a pivotal role in systemic risk propagation during distress times. For instance, Jones (2001) uses a network framework to model foreign exchange market trading decisions. Their model captures some behavioral aspects of currency trading and applies to arbitrage, hedging and speculation of currency risk. van den End and Tabbae (2012) investigate the behavioral responses by banks during the recent crisis. They show that these responses have been increasingly dependant across banks and provide an evidence of herding in the interbank market during the crisis. They also show that banks decisions regarding balance sheet adjustments have been procyclical. Other studies suggest 
that banks' decisions in the OTC derivatives market are motivated by both hedging and speculation. For instance, Géczy et al. (2007) use survey data and find that nonfinancial firms that have high earnings management incentives are more likely to use derivatives for speculative purposes. Additionaly, Chernenko and Faulkender (2012) decomposes firms use of swap market to manage interest rate risk into hedging and speculation. Similar evidence is provided by Faulkender (2005) and Carter and Sinkey Jr (1998). Moreover, Gao et al. (2015) investigate the impact of the network structure on optimal hedge decisions and find that network features play an important role in determining corporate hedging decisions.

\section{The Market Setup}

In this section, we set up the market and develop a baseline model for the interactions between participants in this market.

\subsection{Market Participants}

The market consists of $N$ banks and a single central counterparty denoted by $H$. Banks operate in both the OTC derivatives market where they trade derivatives contracts and in the interbank market where they can lend and borrow from each other. The liabilities of each bank are composed of interbank liabilities $L_{i}^{B}$ representing funding obtained from the interbank market (e.g. repo); other liabilities $L_{i}^{O}$; and capital $K_{i}$. On

the assets side, a bank has interbank assets $A_{i}^{B}$ representing funding extended to others in the interbank market (e.g. reverse repo); high quality liquid assets $A_{i}^{H L}$; low quality liquid assets $A_{i}^{L L}$; and other assets $A_{i}^{O}$. The balance sheet identity of a bank $i$ can be expressed as:

$$
A_{i}^{B}+A_{i}^{H L}+A_{i}^{L L}+A_{i}^{O}=L_{i}^{B}+L_{i}^{O}+K_{i}
$$

Furthermore, the OTC market includes a single central counterparty denoted as $H$ that provides central clearing services to banks. By clearing a derivatives contract, the central counterparty simultaneously becomes a counterparty to each one of the original parties of the contract and, thus, maintains a neutral position that can be expressed as:

$$
\sum_{i=1}^{N} X_{H i}=\sum_{i=1}^{N} X_{i H}
$$


where $X_{H i}$ is the credit exposure of the central counterparty $H$ to bank $i$, and $X_{i H}$ is the credit exposure of bank $i$ to central counterparty $H$.

\subsection{Market Network}

The market network is comprised of two layers: the OTC derivatives layer and the interbank layer. Both layers follow a core-periphery structure.

\subsubsection{Network Construction}

Craig and von Peter (2014) provide a formal way of constructing a core-periphery network using a block model by which they represent the interbank market. In their model the core banks interact (i.e. lend and borrow) with each other and with other periphery banks. The model sets some restrictions on constructing the network: i) it requires that a core bank be connected to all other core banks; ii) it allows interactions between core and periphery banks; and iii) it does not allow connections between any pair of periphery banks. However, not all financial networks show this exact core-periphery structure. Anand et al. (2017) show that some actual core-periphery financial networks can deviate greatly from a perfect structure as that one suggested by Craig and von Peter (2014).

We use a modified version of the block model of Craig and von Peter (2014) to construct both layers of the market network. We relax the first restriction to allow for high probability of connection among core banks but not necessarily to produce a complete network among them. Our modified block model can be represented as:

$$
\underbrace{\left[\begin{array}{cc}
C C & C P \\
P C & P P
\end{array}\right]}_{\text {Blocks }} \Leftrightarrow \underbrace{\left[\begin{array}{cc}
\rho^{C C}(\text { High }) & \rho^{C P}(\text { Low }) \\
\rho^{P C}(\text { Low }) & \rho^{P P}(\text { Zero })
\end{array}\right]}_{\text {Probablity of Connection }}
$$

where block $C C$ represents the interaction among core banks with a connection probability of $\rho^{C C}$ which is expected to be high, blocks $C P$ and $P C$ represent the interactions among core banks and periphery banks with connection probabilities of $\rho^{C P}$ and $\rho^{P C}$ which are equal and are expected to be low, while block $P P$ represents the interaction among periphery banks which we restrict its probability $\rho^{P P}$ to zero. Core banks are determined based on their relative size in the network. 
Thus, we construct a market network comprising of two layers. The first layer represents the interbank market. The probability of a connection between two core banks in this layer is equal to $\rho^{C C}$. Also, the probability of a connection between a core bank and a periphery bank is set to $\rho^{C P}$. The number of core banks is determined from an empirical data on interbank network as shown in section 5.1. A wiring algorithm is then used to initialize the connections between banks which generates the adjacency matrix $\left[\Theta_{i j}\right]_{\{i, j=1,2, \ldots, N\}}$. Links in the interbank layer represent interbank loans, where $A_{i j}^{B}$ is a loan extended from bank $i$ to bank $j$. The value assigned to each link depends on the relative value of the tow banks connected by this link. The value of an interbank loan given by $i$ to $j, A_{i j}^{B}=L_{j}^{B} \frac{A_{i}^{B}}{\sum_{i} \Theta_{i j} A_{i}^{B}}$. Total interbank liabilities can be estimated as $L^{B}=\sum_{i=1}^{N} L_{i}^{B}$, and total interbank assets can be estimated as $A^{B}=\sum_{i=1}^{N} A_{i}^{B}$. Finally, total interbank assets equal total interbank liabilities given that a bank's interbank liability is another bank's asset.

The second layer represents the OTC derivatives market and depicts the long term relationships in the OTC derivatives market. This layer consists of $N$ banks and a single central counterparty. Each link in this layer represents a potential counterparty from which a bank can choose to enter a derivatives contract with. The number of core banks is determined from empirical data on an OTC derivatives network as shown in section 5.1. A wiring algorithm is used to initialize connections between banks. All core banks are connected to the central counterparty, while they are connected to each other with a probability $\rho^{C C}$. Periphery banks are connected to core banks with a probability $\rho^{P C}$, but they do not connect to each other or the central counterparty. It is worth noting, though, that core banks and the connections of each bank are not necessarily the same in both the OTC derivatives and the interbank layers.

\subsubsection{Network Connectivity}

We use two measures of centrality that are widely used in network analysis to measure interconnectedness of a network: density and degree centrality (Newman, 2010). Density provides a measure of the overall connectivity of the network. It is estimated as the ratio of actual links to the total number of possible links in the network. A rough estimation of this measure can be obtained from the adjacency matrix of each layer of the network. 
Let $d$ be the density of the interbank layer, it can then be estimated as:

$$
d=\frac{\rho^{C C} \cdot N^{\text {CoreB }} \cdot\left(N^{\text {CoreB }}-1\right) / 2+\rho^{C P} \cdot N^{\text {CoreB }} \cdot\left(N-N^{\text {CoreB }}\right)}{N^{\text {CoreB }} \cdot\left(N^{\text {CoreB }}-1\right) / 2+N^{\text {CoreB }} \cdot\left(N-N^{\text {CoreB }}\right)}
$$

where $N^{\text {CoreB } B}$ is the number of core banks in the interbank layer. Furthermore, degree centrality provides a measure of the connectivity of an individual bank. In a given network, degree $k_{i}$ of a bank $i$ is the total number of links it has with other banks. We also distinguish between two measures of degree centrality in the interbank layer. The in-degree $k_{i}^{\text {in }}$ (out-degree $k_{i}^{\text {out }}$ ) which represents the number of links in which the bank is the lender (borrower), where:

$$
k_{i}=k_{i}^{\text {in }}+k_{i}^{\text {out }}
$$

Both measures can be estimated for the OTC derivatives layer similar to the interbank layer.

\subsection{OTC Derivatives Market Dynamics}

In this section, we describe a baseline model of interactions between banks in the OTC derivatives market.

\subsubsection{Trading Strategies}

Banks can use the OTC derivatives market for hedging or speculation as shown by Faulkender (2005). We further assume that a bank's decision to hedge or speculate is determined by two factors, namely its idiosyncratic market risk exposure and its level of risk-aversion.

A bank with a given risk exposure may decide to hedge this exposure by taking a position in the opposite direction, or to speculate on market movements by taking a position in the same direction. Other banks with no risk exposures to manage still can speculate on market movements. We further assume that all banks are risk-averse, meaning that they accept to take more risk only if justified by higher expected returns. However, they have different levels of risk-aversion. That said, we divide banks into two types low riskaverse and high risk-averse. The decisions of high risk-averse bank are limited to hedging, while low risk-averse bank can take hedging or speculation decision. 
Based on the combinations of idiosyncratic exposure and risk-aversion level, three trading strategies are available for banks in the OTC derivatives market as follows:

A- Hedging which can be followed in cases of a low risk-averse bank with an existing idiosyncratic exposure, or a high risk-averse bank with an existing idiosyncratic exposure.

B- Speculation which might be followed in cases of a low risk-averse bank with an existing idiosyncratic exposure, or a low risk-averse bank without an existing idiosyncratic exposure.

C- No-Action which might be followed in case of a high risk-averse bank without an existing idiosyncratic exposure.

The purpose for which a bank uses the OTC derivatives market determines its vulnerability to market risk. Banks face market risk to the extent that their positions are not hedged.

\subsubsection{Trading Mechanism}

Banks use the OTC derivatives market to manage their idiosyncratic risk exposures based on the trading strategies outlined above. For simplicity, we assume that banks are only exposed to idiosyncratic interest rate risk exposures. Additionally, we assume that the only way that banks can hedge or speculate interest rate movements is via the OTC derivatives market using a plain vanilla fixed-for-floating interest rate swap based on a given benchmark market interest rate. Also, trading in the OTC derivatives market is governed by a specific set of rules as follows:

1- Periphery banks trade with core banks.

2- Periphery banks do not trade with other periphery banks.

3- Core banks trade with other core banks.

4- Core banks have no constraints on their capacity to enter into contracts with periphery banks.

5- Each bank trades based on its own strategy (see 3.3.1). 


\subsubsection{Clearing Mechanism}

Derivatives contracts can either be bilaterally or centrally cleared. In either case, cleared contracts generate credit exposures which we quantify below.

For banks $i$ and $j$, let $X_{i j}^{c}$ be the amount that $j$ owes $i$ in position of contract $c$. It then follows that $\max \left(X_{i j}^{c} ; 0\right)$ is the exposure of $i$ to $j$ in contract $c$. This exposure is the amount counterparty $i$ risks losing upon the default of counterparty $j$. Also, let $C^{i j}$ be the set of all outstanding contracts between $i$ and $j$. It follows that the net exposure of $i$ to $j$ can be expressed as $X_{i j}=\max \left\{\sum_{c=1}^{C^{i j}} X_{i j}^{c}, 0\right\}$. Furthermore, let $X_{i}$ be the aggregate exposure of $i$. If all $i$ 's contracts are bilaterally cleared, it is exposed to different counterparties, and its net exposure can be expressed as:

$$
X_{i}=\sum_{j \neq i}^{N} \max \left\{\sum_{c=1}^{C^{i j}} X_{i j}^{c}, \quad 0\right\}
$$

Similarly, if all $i$ 's contracts are centrally cleared, $i$ is exposed only to the central counterparty $H$. Let $C^{i H}$ be the set of all $i$ 's outstanding contracts that are centrally cleared with $H$, and $X_{i H}^{c}$ be the exposure of $i$ to $H$ in contract $c$. It follows that $i$ 's net exposure can be expressed as:

$$
X_{i}=\max \left\{\sum_{c=1}^{C^{i H}} X_{i H}^{c}, 0\right\} .
$$

Finally, let us assume that a percentage $\omega$ of all $i$ 's contracts is centrally cleared, while $(1-\omega)$ is bilaterally cleared, and that $C^{i}$ is the set of all $i$ 's outstanding contracts where $C^{i}=C^{i H}+\sum_{j \neq i}^{N} C^{i j}, C^{i H}=\omega \times C^{i}$ and $\sum_{j \neq i}^{N} C^{i j}=(1-\omega) \times C^{i}$. Thus, the net exposure of $i$ to the central counterparty $H$ and all other counterparties $j \neq i$ can be obtained by combining Eq. 5 and 6 as follows:

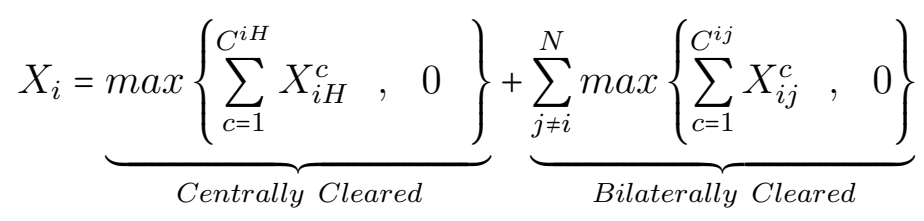

\subsubsection{Margin Calls}

A cleared contract results in two types of exposures: the potential future exposure which is mitigated by the initial margin, and the current exposure which is mitigated by variation margin (Lin and Surti, 2015). Given our focus on margin procyclicality due to 
market fluctuations, we use a single measure to quantify both exposures as illustrated in 3.3.3. Hence, we do not explicitly consider a contract's initial margin. Instead, our focus here is on variation margin.

The market value of the swap contract changes with market fluctuations. More specifically, the sensitivity of the swap value to changes in the market interest rate can be approximated by modified duration (Smith, 2011). Following the same logic, we approximate the modified duration of a swap contract by $\beta$ which represents the sensitivity of the swap value to a one basis-point change in the benchmark market interest rate $R_{m}$. Thus, for the pay-fixed side (long) of a swap contract, the basis-point change in the swap's market value $\Delta V$ can be estimated as a function of the change in market interest rate $\Delta R_{m}$ and $\beta$ as follows:

$$
\Delta V=\beta \cdot \Delta R_{m}
$$

where $\Delta V$ is measured per dollar of notional amount, and $\Delta R_{m}$ is measured in basis points. We estimate the change in market interest rate as a stochastic process using the Hull-White single factor model (Hull and White, 1990). For the receive-fixed side (short), the change in the swap's market value is $-\Delta V$. For instance, if market interest rates increase, the new swap rates will be higher. As a result, the pay-fixed side of the swap makes a profit as the market value of its contract increases, while the receive-fixed side makes a loss due to the decline in the market value of its contracts. This implies that the direction of $\Delta V$ depends on the direction of $\Delta R_{m}$.

Due to changes in the market value of the swap contracts outstanding between banks $i$ and $j$, the net exposure of $i$ to $j$ fluctuates leading to variation margin calls if necessary. If $i$ 's aggregate exposure to $j$ increases, $i$ should recehive a variation margin from $j$, and vice versa. Let $\Delta X_{i j}$ be the the aggregate change of $i$ 's exposure to $j$, it follows from Eq. 8 that:

$$
\Delta X_{i j}=\underbrace{\sum_{c=1}^{C^{i j+}} \Delta V \cdot B^{c}}_{\text {Pay-fixed }}+\underbrace{\sum_{c=1}^{C^{i j-}-}-\Delta V \cdot B^{c}}_{\text {Receive-fixed }}
$$

where $B^{c}$ is the notional amount of contract $c . C^{i j+}$ and $C^{i j-}$ are the set of all contracts 
between $i$ and $j$ in which $i$ is the pay-fixed side and pay-floating side, respectively. Now, let $v_{i j}$ be the variation margin required from bank $i$ and due to bank $j$, it then follows that:

$$
v_{i j}=\max \left\{\Delta X_{j i} \quad, \quad 0\right\}
$$

where $\Delta X_{j i}$ is the the aggregate change of $j$ 's exposure to $i$ which is equal to $-\Delta X_{i j}$. Following the same intuition as in Eq. 5-7, the total variation margin required from bank $i, v_{i}$, can be estimated as:

$$
v_{i}=\underbrace{v_{i H}}_{\text {Centrally Cleared }}+\underbrace{\sum_{j \neq i}^{N} v_{i j}}_{\text {Bilaterally Cleared }}
$$

where $v_{i H}$ is the variation margin required from $i$ and due to the central counterparty $H$. We discuss how banks meet their variation margin calls in the following section.

\section{Contagion and Systemic Risk}

In this section, we analyse the potential contagion in the interbank market due to distress spillover from the OTC derivatives market.

\subsection{Distress Origination}

As illustrated in 3.1, banks have holdings of both high quality liquid assets $A^{H L}$ and low quality liquid assets $A^{L L}$. Variation margin calls can only be paid using $A^{H L}$, but not $A^{L L}$. This implies that banks may come under distress if their holdings of $A^{H L}$ are not sufficient to cover a margin call. To illustrate this, assume that due to high market interest rates volatility, a bank $i$ is faced with an outsize variation margin call. Formally, the condition under which bank $i$ becomes distressed is:

$$
A_{i}^{H L}-v_{i}<0
$$

Eq. 12 implies that sufficiently high variation margins have the potential to trigger a liquidity shortage at the bank. If a bank faces such a liquidity shortage, it needs to take defensive actions to avoid defaulting on required payments. We assume that the only way banks can obtain new funding is through the interbank market. 


\subsection{Price of Liquidity}

Distressed banks with insufficient holdings of $A^{H L}$ have two options to secure funding to cover their variation margin calls. The first is to withdraw their lending extended to other banks in the interbank market. In this case, the bank pays exit fees for prematurely calling the loan. Let $\gamma_{i}$ be the exit fees that the bank $i$ has to pay. Thus, the maximum amount of $A^{H L}$ that $i$ can obtain by withdrawing its lending from the interbank market is given by:

$$
A_{i}^{H L}=\left(1-\gamma_{i}\right) A_{i}^{B}
$$

The second option available for distressed banks to secure additional funding is to use $A^{L L}$ as collateral to obtain $A^{H L}$ from the interbank market. In this case, the bank is faced with two types of haircut that will be applied to $A^{L L}$. The first is a system-wide haircut $\alpha \in[0,1]$ which reflects the perceived system wide liquidity risk of $A^{L L}$ compared to $A^{H L}$. The second is a bank-specific haircut $\alpha_{i} \in[0,1]$ to reflect the idiosyncratic risk associated with a given bank. Therefore, the maximum amount of $A^{H L}$ that bank $i$ can obtain using its holdings of $A^{L L}$ as collateral is given by:

$$
A_{i}^{H L}=\left(1-\alpha-\alpha_{i}\right) A_{i}^{L L}
$$

where $\alpha+\alpha_{i}<1$, which is necessary to put a non-negative lower bound on the amount of $A^{H L}$ obtained using $A^{L L}$.

A bank's decision to follow a specific funding option of the above depends on its cost to the bank. Thus, it follows from Eq. 13 and 14 that liquidity hoarding will continue as long as it is less costly compared to using less liquid assets as collateral. Formally, when:

$$
\gamma_{i}<\left(\alpha+\alpha_{i}\right)
$$

In other words, when the amount of $A^{H L}$ that a bank can obtain by withdrawing a given amount of interbank lending is higher than the amount of $A^{H L}$ that can be obtained by pledging an equal amount of less liquid assets. 


\subsection{Liquidity Hoarding Contagion}

When banks decide to withdraw their lending from the interbank market, this may lead to a liquidity hoarding contagion. We propose a liquidity hoarding contagion mechanism in the spirit of Gai et al. (2011). To illustrate the dynamics of this liquidity hoarding contagion, assume that a bank $i$ becomes distressed as illustrated by Eq. 12. According to Eq. 15, the bank hoards liquidity from the interbank market to cover its liquidity shortage if $\gamma_{i}<\left(\alpha+\alpha_{i}\right)$. Further, assume that the bank withdraws an additional amount of interbank lending as a precautionary action for subsequent margin calls. This amount can be estimated as a fraction of its current margin call $v_{i}$. Let $A_{i}^{h}$ be the amount hoarded which can be estimated as:

$$
A_{i}^{h}=\frac{(1+\lambda) v_{i}-A_{i}^{H L}}{\left(1-\gamma_{i}\right)}
$$

where $\lambda$ is called the liquidity hoarding multiplier. Similarly, if $\gamma_{i}>\left(\alpha+\alpha_{i}\right)$, the bank sells an amount of its less liquid assets to cover its liquidity shortage and obtain the precautionary liquidity. Let $A_{i}^{s}$ be the amount sold which can be estimated as:

$$
A_{i}^{s}=\frac{(1+\lambda) v_{i}-A_{i}^{H L}}{\left(1-\alpha-\alpha_{i}\right)}
$$

Now assume that $i$ is connected to a group of $k_{i}^{i n}$ banks through its interbank lending transactions. Also, assume that bank $i$ 's interbank withdrawals are proportionally distributed among its borrowers. For contagion to spread beyond $i$, there should be at least one bank $j \in k_{i}^{i n}$ for which the following condition holds:

$$
A_{j}^{H L}-v_{j}-\left(A_{i j}^{B} \cdot \frac{A_{i}^{h}}{A_{i}^{B}}\right)<0
$$

Eq. 18 provides the tipping point for liquidity distress, that arise at bank $i$, to become systemic and spread to other banks.

Once bank $i$ starts to hoard liquidity and Eq. 18 is satisfied for other banks, liquidity shortages can propagate through the network of interbank linkages. Subsequently, we can derive the general condition under which any bank $j$ becomes distressed as follows:

$$
A_{j}^{H L}-v_{j}-\left(\sum_{i}^{k_{j}^{\text {out }}} A_{i j}^{B} \cdot \frac{A_{i}^{h}}{A_{i}^{B}}\right)<0
$$


where $k_{j}^{\text {out }}$ is the group of bank $j$ lenders. Thus, a bank becomes distressed if the total amount of its available $A_{j}^{H L}$ is not sufficient to cover its variation margin, after accounting for the loss of interbank funding that it might experience due to liquidity hoarding by its counterparties.

\subsection{Systemic Risk}

Finally, we estimate the overall impact of distress spillover from the OTC derivatives market as the cost of liquidity hoarding in the interbank market and the cost of selling less liquid assets. We then estimate the systemic loss as the ratio of this amount to as a percentage of the initial amount of interbank assets. It then follows that:

$$
\Phi=\frac{\sum_{i=1}^{N} \gamma_{i} A_{i}^{h}+\sum_{i=1}^{N}\left(\alpha+\alpha_{i}\right) A_{i}^{s}}{\sum_{i=1}^{N} A_{i}^{B}}
$$

where $\Phi$ is an approximation to the systemic loss that the system encounters due to liquidity hoarding or selling less liquid assets.

\section{Model Calibration and Validation}

In this section, we calibrate the parameters used in the model to approximate the basic characteristics of the OTC derivatives and interbank markets, and provide an overview of the simulation framework.

\subsection{Model Calibration}

We calibrate the model using data of the US banking system as of 31 December $2016 .^{2}$ Table 1 displays the values used. Given that we are interested in banks that are active in both the OTC derivatives market and the interbank market, we base our parameters estimation on the group of insured commercial banks with assets greater than $\$ 3$ billion. That said, we set the number of banks in our model equal to 245 . For each bank, the amount of total assets is set as $A_{i} \in[100 ; 70,000]$ which are drawn from a powerlaw distribution with power law exponent of 1.75 which is estimated directly from the data set. The composition of each bank's balance sheet is determined randomly

\footnotetext{
${ }^{2}$ Data is obtained from the web site of the Federal Financial Institutions Examination Council (FFIEC) and is available at https://www.ffiec.gov/nicpubweb/nicweb/nichome.aspx
} 
as percentages of total assets with parameters drawn from uniform distributions as follows. ratio of interbank assets $A_{i}^{B} \approx U(0.1 \%, 10 \%)$, ratio of high quality liquid assets $A_{i}^{H L} \approx U(1 \%, 5 \%)$, ratio of low quality liquid assets $A_{i}^{L L} \approx U(10 \%, 30 \%)$, ratio of interbank liabilities $L_{i}^{B} \approx U(0.1 \%, 10 \%)$, ratio of equity $K_{i} \approx U(7 \%, 15 \%)$. Finally, other assets are set as $A_{i}^{O}=A_{i}-\left(A_{i}^{B}+A_{i}^{H L}+A_{i}^{L L}\right)$, and other liabilities are set as $L_{i}^{O}=A_{i}-\left(L_{i}^{B}+K_{i}\right)$.

\section{[ Insert Table 1 about here ]}

We construct the market network of both the interbank and the OTC derivatives layers as a core-periphery structure following (Craig and von Peter, 2014). The number of core banks is determined based on the relative size of each bank's assets in a specific layer of the network. To estimate this, we first rank banks and calculate the difference in the log of assets of each bank and its succeeding bank. Banks with difference higher that 0.10 are taken to be the core banks. Based on this, the number of core banks in the interbank layer is set equal to 16 banks, and in OTC derivatives layer is set equal to 9 banks. The core-core probability of connection $\rho_{C C}$ is set equal to 0.65 , and the core-periphery probability of connection $\rho_{D C}$ is set equal to 0.15 .

The percentage of centrally cleared contracts is set equal to $72 \%$ as reported by the International Swaps and Derivatives Association in its OTC Derivatives Market Analysis on interest rate derivatives published in December 2016 (ISDA, 2016). Following the interest rate swaps stress test developed by the Commodities and Futures Trading Commission (CFTC, 2016), we use a market interest rate change of 60 basis points to estimate the change in value of the swap contracts. In addition, we use a system wide haircut percentage of $10 \%$ similar to that percentage recommended by the Bank for International Settlements (BIS-IOSCO, 2013). The bank specific hair cut $\alpha_{i}$ is drawn from a uniform distribution $U(0 \%, 5 \%)$. We set the sensitivity of a derivatives contract value to market interest rate risk $\beta$ equal to 2 , and the liquidity hoarding cost equal to 0.05 . Finally, we set the propensity for liquidity hoarding equal to 1 as in Gai et al. (2011).

\subsection{Model Validation}

We validate the model to confirm that it produces interbank and OTC derivatives markets that resemble the real markets based on individual bank decisions on trading in 
the OTC derivatives market. The model is validated based on a comparison between the features of the model's network topology and those features observed in read data.

\section{[ Insert Figure 1 about here ]}

Degree distribution of both the derivatives and the interbank layers of the market network are shown in Figure 1. The figure shows the cumulative density function (CDF) of the degree distribution. The power law exponents are 1.75 in the case of the interbank layer and 2.15 in the case of the derivatives layer. Overall, these distributions show a good match with typical core-periphery networks from different markets including Germany (Craig and von Peter, 2014), Italy (Fricke and Lux, 2015), Mexico (Martinez-Jaramillo et al., 2014), U.K. (Langfield et al., 2014), and U.S. (Li and Schürhoff, 2014; Markose et al., 2012).

\section{Results}

In this section, we describe the main results of our paper. We first provide an overview of the simulations framework. Then, we provide the results of a baseline simulation based on the initial parameters as shown in Table 1. Finally, we extend the analysis to explore the impact of central clearing, interconnectedness and other factors on the distress spillover from the OTC derivatives market to the interbank market.

\subsection{Simulations Framework}

The procedure of the model is illustrated by Figure 2. At the beginning of the simulation, $\mathrm{t}=0$, banks' balance sheets, the interbank network are set up according to the initial values of parameters as shown in Table 1 . At $\mathrm{t}=1$, banks develop their own strategies, then trading and clearing take place in the OTC derivatives market as shown in section 3.3. At $\mathrm{t}=2$, margin calls are calculated as derived in Eq. 11. For each bank, distress is assessed based on Eq. 12. Then, based on the available funding options, the tipping point for liquidity hoarding contagion is assessed as in Eq. 18. Finally, systemic loss is approximated as shown by Eq. 20.

[ Insert Figure 2 about here ] 
We typically run 100 simulations and report the average. The main output of each simulation is the systemic loss due to liquidity hoarding and the number of distressed banks. The baseline simulation is based on the initial values of the model parameters. Some of these values are adjusted in the subsequent experiments to test other hypotheses.

\subsection{Systemic Liquidity Risk}

As a benchmark, we begin by analysing the dynamics of distress spillover from the OTC derivative market to the interbank market. The main factor of impact here is margin procyclicality as derived by the change in the benchmark market interest rate $\Delta R_{m}$. The change in $\Delta R_{m}$ affects all contracts simultaneously. This is similar to a parallel shift in the zero yield curve. We do not explicitly model any convexity effect of the interest rate change as the modified duration $\beta$ is assumed to account for this effect. Figure 3 shows the systemic loss and the number of distressed banks over a range of 0 to 100 basis point of $\Delta R_{m}$.

\section{[ Insert Figure 3 about here ]}

The dynamics of systemic risk captured in this figure varies as follows. At low levels of $\Delta R_{m}$, the change in value of derivatives contracts is limited and lead only to normal variation margin calls that can be met by normal holdings of high quality liquid assets. The level of systemic risk in this case is at its minimum level and none of the banks is distressed. As the level of $\Delta R_{m}$ increases to moderate levels, the distress spillover tipping point is reached. The change in value of derivatives contracts lead to variation margin calls that exceed the holdings of high quality liquid assets of some banks. The only option available for these banks to fund their margin calls is to hoard liquidity from the interbank market. This is due to the fact that in our benchmark model the liquidity hoarding cost is less than the total haircut that these banks might be subject to if they try to sell less liquid assets. The level of systemic risk at this stage is still limited due to the fact that distressed banks are small banks with limited share in the interbank lending and borrowing activities. At high levels of $\Delta R_{m}$, the change in value of derivatives contracts becomes significant and the number of banks with variation margin calls that exceed their normal holdings of high quality liquid assets increases. At this stage, the level of systemic risk becomes significant due to the fact that some interbank dealers become distressed. 
When a dealer decides to hoard liquidity, systemic loss increases significantly because of the dealer's large share in the interbank lending and borrowing activities.

Thus, our benchmark model seems to be consistent with the findings of Lee (2013) that the interbank market can be vulnerable to systemic liquidity shortages due to knockon effects through interbank linkages. Our findings are also consistent with the evidence on herding in the interbank market during the financial crisis of 2008 (van den End and Tabbae, 2012). Moreover, these findings give rise to the importance of prudent liquidity risk management practices at the bank level that consider systemic implications of financial distress. Banks should maintain sufficient liquidity to limit the chances that high margin requirements would cause liquidity distress for them. In addition, the impact of market volatility should be adequately accounted for when setting liquidity coverage ratios of banks as required by the new Basel III standards.

\subsection{Impact of Central Clearing}

We now move to assess the impact of central clearing compared to bilateral clearing on the distress spillover from the OTC derivatives market into the interbank market. We assume that an average percentage $\omega$ of all the derivatives contracts traded is centrally cleared through the central counterparty. However, unlike the benchmark case in which we calibrate $\omega$ to be $72 \%$, here we assess systemic risk over the whole range of central clearing from $0 \%$ to $100 \%$.

\section{[ Insert Figure 4 about here ]}

Figure 4 shows the results of this exercise which reveal a striking finding. The percentage of centrally cleared contracts compared to bilaterally cleared contracts positively affects the systemic risk propagation within the interbank market. The systemic liquidity hoarding increases with $\omega$, although not significantly. One reason that explains this finding is the difference in the timing of cash flows under central and bilateral clearing. Although the value of margin calls are the same, in practice the timing of cash flows is different. In the case of central clearing, banks with negative values are required to post their margin requirements immediately while banks with positive values receive their margin in the following period. Conversely, in the case of bilateral clearing all cash flows 
are received at the same period. This implies that banks can use these receipts from margin calls as caution against sudden liquidity withdrawal which limits the systemic liquidity risk in the case of bilateral clearing compared to central clearing.

Our findings about the impact of central clearing on systemic liquidity risk complements previous studies that focus on its impact on counterparty credit risk (e.g. Acharya and Bisin, 2014; Loon and Zhong, 2014) and collateral demand (e.g. Duffie and Zhu, 2011; Cont and Kokholm, 2014; Garratt and Zimmerman, 2015). We focus on the dayto-day margining and funding practices in OTC derivatives markets. Our finding that central clearing might in fact increase systemic liquidity risk sheds light on the overlooked impact of margin requirements on funding liquidity risk. An impact that arises due to margin procyclicality which occurs when margin requirements rise at times of market stress, leading to even more stress. Also, these findings emphasize the need of banks to consider the impact of central clearing on their margin requirements and accordingly liquidity risk management. Banks with derivatives exposures that are being moved from bilateral clearing to central clearing as required by regulations should expect increases in required daily cash flows to meet their margin requirements. Thus, banks should adequately account for this adverse impact of central clearing when setting liquidity coverage ratios.

\subsection{Impact of Interconnectedness}

Next, we assess the impact of interconnectedness in the interbank market on the propagation of systemic risk within the system. We use density as shown by Eq. 3 as a measure of interconnectedness of the interbank network. The value of the network density in the benchmark scenario is calibrated to be 0.15 . Here, we explore the dynamics of the model over a range for density from 0.01 to 0.25 , while using the same values of other parameters as in the benchmark model.

Figure 5 shows the results of this exercise. As can be seen form Panel (A) the value of systemic risk seems to be unaffected by the level of connectivity within the interbank market. This finding might seem counterintuitive at first sight given numerous studies that confirm the role of interconnectedness in systemic risk propagation (see e.g. Eisen- 
berg and Noe, 2001; Furfine, 2003; Freixas et al., 2000; Allen and Gale, 2000). However, this might be justified by considering that systemic risk is measured as the system wide loss due to liquidity shortage at some banks which results from elevated margin calls. These margin calls originate in the OTC derivatives market and are not affected by the degree of connectivity in the interbank market. Nevertheless, interconnectedness in the interbank market affects the number of distressed banks as shown in Panel (B). At higher levels of connectivity, when a bank decides to withdraw funding it affects more banks and the same level of systemic liquidity loss is divided between a larger number of banks. This explains why systemic loss is not affected while the number of distressed banks increases with density.

\section{[ Insert Figure 5 about here ]}

In addition, the results shown here highlights another adverse impact of interconnectedness on bank risk. It is widely argued that interconnectedness affects counterparty credit risk either through concentration of exposures or through boosting default propagation in dense networks. Nevertheless, as we show here, interconnectedness can also affect liquidity risk adversely through its impact on the propagation of liquidity distress within the interbank market network. Banks, thus, need to take a proactive approach to liquidity risk management by actively monitoring interconnectedness on an ongoing basis. But given that interconnectedness cannot be observed by a single bank as it requires mapping all counterparties data to identify and illustrate overall exposures, there is a need for a system regulator to monitor any concentration of risk that might result in unexpected losses. Still, a bank needs to ensure that it has accurate and reliable data about its own counterparties to ensure it becomes aware of any areas in which interconnectedness is introducing more risk than expected. A bank can then adjust its reserves and change its strategy while there is still time before being hit by liquidity distress from other banks.

\subsection{Impact of Haircut}

In this exercise, we assess the impact of haircut rates on the propagation of systemic liquidity risk in the interbank market. The dynamics in systemic risk in this case results from the change in the average haircut that a bank might be subject to when selling less 
liquid assets to fund a margin call. The average haircut includes both the system wide haircut and the average bank-specific haircut $\alpha+\overline{\alpha_{i}}$. Here, we explore the dynamics of the model over a range for the haircut from 0.01 to 0.10 , while using the same values of other parameters as in the benchmark model.

The results are shown in Figure 6. Panel (A) shows that systemic risk is negligible for a haircut set at low level. It then increases with the increases in the haircut level, and finally converges to a level similar to those obtained in the benchmark model. Recall that a distressed bank has two options to fund a margin call: interbank liquidity withdrawals and selling less liquid assets. The decision of selecting one option over the other depends on the comparison between the cost of liquidity hoarding $\gamma$ and the average total haircut $\alpha+\bar{\alpha}_{i}$. Given that the maximum cost of liquidity hoarding $\gamma$ is set to be 0.05 , a distressed bank will sell less liquid assets as long as $\left(\alpha+\bar{\alpha}_{i}\right)<0.05$. Beyond this threshold, a distressed bank finds it less costly to hoard liquidity from the interbank market with a cost that is capped at 0.05 as in the benchmark model. The same notion is confirmed in Panel (B). The number of distressed banks increase with the the increase in haircut as more banks would now withdraw liquidity from the interbank market leading other banks to become distressed.

\section{[ Insert Figure 6 about here ]}

The findings shown in this section provide some insight into the role of liquidity provider of last resort. In distress times, a central bank may stand ready to act as a temporary market maker of last resort by providing low haircut rates for banks willing to fund their liquidity needs. The aim would be to improve the liquidity of distressed banks and limit the spillover of distress to other market participants. Also, these findings have some implications at the bank level. An effective liquidity risk management framework should consider the possibility and expected levels of haircuts during distress times. This implies that banks should ensure that their holdings of liquid assets are of sufficient quality to limit the possibility that they would be subject to high levels of haircuts in times of financial distress. In addition, the impact of haircuts should be adequately accounted for when setting liquidity coverage targets. 


\subsection{Sensitivity Analysis}

The effect of margin procyclicality on systemic liquidity risk depends on some modelling assumptions. In this section, we explore how the implications for distress spillover from the OTC derivatives market to the interbank market change when we modify some assumptions of the benchmark model.

\subsubsection{Liquidity hoarding multiplier}

The liquidity hoarding multiplier $\lambda$ is used to capture the average level of panic in the interbank market. In the benchmark model we assumed that banks hoard liquidity only to the extent that covers their liquidity needs in the OTC derivatives market. However, the interbank market has witnessed times of a lending freeze and high levels of liquidity hoarding during the financial crisis of 2008 (van den End and Tabbae, 2012). Thus, it is reasonable to assume higher levels for $\lambda$. We run another simulation to explore the dynamics of systemic risk using a range of $\lambda \in[1,3]$. The results are shown in Figure 7. Both systemic loss and the number of distressed banks increase with the increase in $\lambda$. This result confirms the notion that when uncertainty increases in the interbank market banks hoard larger amounts of liquidity which leads to more panic and increases the number of banks that become distressed.

\section{[ Insert Figure 7 about here ]}

\subsubsection{Modified duration}

In our model, market interest rate change is assumed to be common across all the derivatives contracts. It cannot be hedged or diversified away and lead to changes in the contract value. The sensitivity of a derivatives contract to changes in market interest rates is approximated by $\beta$ as illustrated by Eq. 8. In our baseline calibration, we set $\beta=2$. However, it is entirely possible that real values of $\beta$ can be lower or higher than this value. We run another simulation to explore the dynamics of systemic risk using a range of $\beta \in[0,3]$. The results are shown in Figure 8. As illustrated, systemic risk is limited at low levels of $\beta$. Nevertheless, both systemic loss and the number of distressed banks increase with further increases in $\beta$. This result confirms the notion that higher sensitivity leads to higher changes in the derivatives contract value which in turn results 
in higher margin calls. The elevated margin calls make more banks vulnerable to liquidity shortage and increases systemic loss.

[ Insert Figure 8 about here ]

\section{Conclusion}

In this paper, we explore the distress spillover from the OTC derivatives market into the interbank market. We focus on the impact of margin procyclicality in the OTC derivatives market on systemic liquidity risk in the interbank market.Our work brings together the micro-structure and the macro-structure of these markets within a quantitative framework to show how market volatility would lead to contagion among market participants. In so doing, we focus on a specific question that has recently risen to the top of policy agendas: how does margin requirements coupled with interbank propensity for liquidity hoarding affect the systemic risk propagation in a financial network of banks?

Given that the model reproduces the qualitative features of the data, we use it to investigate some of the policy implications of margin requirements. To this end, the general approach followed is to perturb the OTC derivatives market with an interest rate shock and analyse the systemic risk propagation within the interbank market. The model demonstrates that margin procyclicality derived by interest rate volatility can lead to the onset of a systemic liquidity shortage within the interbank market. It also shows that central clearing might in fact increase the possibility of a systemic liquidity crisis due to tight margin requirements. Consistent with previous evidence, the model predicts that interconnectedness amplifies the effect of systemic risk. The model also shows that haircut levels affects the possibility of a systemic liquidity crisis, and highlights the potential role of a market maker of last resort in limiting this possibility.

Overall, the results of our paper illustrate the tension between the micro-level decisions of individual banks and the macro-level outcomes of these decisions. During stress time, banks make decisions about their interbank lending that are rational from each individual bank perspective. However, from a systemic perspective, these decisions generate undesirable results. A decision of a single bank to hoard liquidity in the interbank 
market might spread the liquidity hoarding contagion to other banks causing systemic loss. This systemic loss results from the cost of liquidity withdrawals of interbank lending which are endogenously driven by bank's propensity for liquidity hoarding during distress times. This contagion dynamic is thus characterized by a self fulfilling process among banks.

Our model is the first attempt to analyze the effects of margin requirements on systemic liquidity risk. Since the model is stylized, it abstracts from some important factors that could affect our conclusion. For instance, the model does not consider the possibility that selling less liquid assets could lead to a fire sale and distress asset prices. Also, we consider only one type of derivatives contracts, and thus it is not straightforward to generalize the results to all types of OTC derivatives exposures. Nevertheless, the work presented here can be extended in different ways. For example, different structures of the financial network can be investigated to explore the effect on systemic risk propagation. Also, It would be helpful to investigate the extent to which a bank is subject to margin procyclicality based on its risk aversion which plays an important role in the direction of its trades. Finally, another extension may involve the effects of banks' balance sheet heterogeneity on the systemic risk propagation. 


\section{References}

Acharya, V., Bisin, A., 2014. Counterparty risk externality: Centralized versus over-thecounter markets. Journal of Economic Theory 149, 153-182.

Acharya, V. V., Gale, D., Yorulmazer, T., 2011. Rollover risk and market freezes. The Journal of Finance 66 (4), 1177-1209.

Acharya, V. V., Skeie, D., 2011. A model of liquidity hoarding and term premia in interbank markets. Journal of Monetary Economics 58 (5), 436-447.

Acharya, V. V., Yorulmazer, T., 2008. Information contagion and bank herding. Journal of Money, Credit and Banking 40 (1), 215-231.

Allen, F., Carletti, E., Gale, D., 2009. Interbank market liquidity and central bank intervention. Journal of Monetary Economics 56 (5), 639-652.

Allen, F., Gale, D., 2000. Financial contagion. Journal of Political Economy 108 (1), $1-33$.

Anand, K., Gai, P., Marsili, M., 2012. Rollover risk, network structure and systemic financial crises. Journal of Economic Dynamics and Control 36 (8), 1088 - 1100, quantifying and Understanding Dysfunctions in Financial Markets.

Anand, K., van Lelyveld, I., dm Banai, Friedrich, S., Garratt, R., Haaj, G., Fique, J., Hansen, I., Jaramillo, S. M., Lee, H., Molina-Borboa, J. L., Nobili, S., Rajan, S., Salakhova, D., Silva, T. C., Silvestri, L., de Souza, S. R. S., 2017. The missing links: A global study on uncovering financial network structures from partial data. Journal of Financial Stability.

Aymanns, C., Farmer, J. D., 2015. The dynamics of the leverage cycle. Journal of Economic Dynamics and Control 50, 155 - 179.

Battiston, S., Gatti, D. D., Gallegati, M., Greenwald, B., Stiglitz, J. E., 2012. Liaisons dangereuses: Increasing connectivity, risk sharing, and systemic risk. Journal of Economic Dynamics and Control 36 (8), 1121 - 1141.

BIS-IOSCO, 2013. Margin requirements for non-centrally cleared derivatives. Bank for International Settlements and International Organization of Securities Commissions. available at: http://www.bis.org/publ/bcbs261.pdf [accessed 15 nov. 2017].

BIS-IOSCO, 2015. Margin requirements for non-centrally cleared derivatives (revised). Bank for International Settlements and International Organization of Securities Commissions.available at: https://www.bis.org/bcbs/publ/d317.htm [accessed 15 nov. 2017].

Bolton, P., Santos, T., Scheinkman, J. A., 2011. Outside and inside liquidity. The Quarterly Journal of Economics 126 (1), 259-321.

Brossard, O., Saroyan, S., 2016. Hoarding and short-squeezing in times of crisis: Evidence from the euro overnight money market. Journal of International Financial Markets, Institutions and Money 40 (Supplement C), 163 - 185. 
Brunnermeier, M. K., Pedersen, L. H., 2009. Market liquidity and funding liquidity. Review of Financial Studies 22 (6), 2201-2238.

Caballero, R. J., Krishnamurthy, A., 2008. Collective risk management in a flight to quality episode. The Journal of Finance 63 (5), 2195-2230.

Caccioli, F., Farmer, J. D., Foti, N., Rockmore, D., 2015. Overlapping portfolios, contagion, and financial stability. Journal of Economic Dynamics and Control 51, 50 63.

Carter, D. A., Sinkey Jr, J. F., 1998. The use of interest rate derivatives by end-users: the case of large community banks. Journal of Financial Services Research 14 (1), 17-34.

CFTC, 2016. Supervisory stress test of clearinghouses. Commodity Futures Trading Commission, November.

Chernenko, S., Faulkender, M., 2012. The two sides of derivatives usage: Hedging and speculating with interest rate swaps. Journal of Financial and Quantitative Analysis 46 (06), 1727-1754.

Cifuentes, R., Ferrucci, G., Shin, H. S., 2005. Liquidity risk and contagion. Journal of the European Economic Association 3 (2-3), 556-566.

Cont, R., Kokholm, T., 2014. Central clearing of OTC derivatives: bilateral vs multilateral netting. Statistics \& Risk Modeling 31 (1), 3-22.

Craig, B., von Peter, G., 2014. Interbank tiering and money center banks. Journal of Financial Intermediation 23 (3), $322-347$.

Danielsson, J., Shin, H. S., Zigrand, J.-P., 2012. Procyclical leverage and endogenous risk. Available at SSRN: https://ssrn.com/abstract=1360866.

Danielsson, J., Zigrand, J.-P., 2008. Equilibrium asset pricing with systemic risk. Economic Theory 35 (2), 293-319.

Diamond, D. W., Rajan, R. G., 2011. Fear of fire sales, illiquidity seeking, and credit freezes. The Quarterly Journal of Economics 126 (2), 557-591.

Duffie, D., Zhu, H., 2011. Does a central clearing counterparty reduce counterparty risk? Review of Asset Pricing Studies 1 (1), 74-95.

Eisenberg, L., Noe, T. H., 2001. Systemic risk in financial systems. Management Science 47 (2), 236-249.

Eross, A., Urquhart, A., Wolfe, S., 2016. Liquidity risk contagion in the interbank market. Journal of International Financial Markets, Institutions and Money 45 (Supplement C), $142-155$.

Faulkender, M., 2005. Hedging or market timing? selecting the interest rate exposure of corporate debt. The Journal of Finance 60 (2), 931-962.

Fostel, A., Geanakoplos, J., 2012. Why does bad news increase volatility and decrease leverage? Journal of Economic Theory 147 (2), 501-525. 
Freixas, X., Parigi, B. M., Rochet, J.-C., 2000. Systemic risk, interbank relations, and liquidity provision by the central bank. Journal of Money, Credit and Banking 32 (3), 611-638.

Fricke, D., Lux, T., 2015. Core-periphery structure in the overnight money market: evidence from the e-mid trading platform. Computational Economics 45 (3), 359-395.

Furfine, C., 2003. Interbank exposures: Quantifying the risk of contagion. Journal of Money, Credit, and Banking 35 (1), 111-128.

Gai, P., Haldane, A., Kapadia, S., 2011. Complexity, concentration and contagion. Journal of Monetary Economics 58 (5), 453-470.

Gao, T., Gupta, A., Gulpinar, N., Zhu, Y., 2015. Optimal hedging strategy for risk management on a network. Journal of Financial Stability 16, 31 - 44.

Garratt, R., Zimmerman, P., 2015. Does central clearing reduce counterparty risk in realistic financial networks? Federal Reserve Bank of New York Staff Reports No. 717.

Geanakoplos, J., 2010. The leverage cycle. NBER macroeconomics annual 24 (1), 1-66.

Geanakoplos, J., Pedersen, L. H., 2012. Monitoring leverage. In: Risk Topography: Systemic Risk and Macro Modeling. University of Chicago Press, pp. 113-127.

Géczy, C. C., Minton, B. A., Schrand, C. M., 2007. Taking a view: Corporate speculation, governance, and compensation. The Journal of Finance 62 (5), 2405-2443.

Gorton, G., Metrick, A., 2012. Securitized banking and the run on repo. Journal of Financial Economics 104 (3), 425-451.

Gorton, G. B., 2010. Slapped by the invisible hand: The panic of 2007. Oxford University Press.

Grossman, S. J., Miller, M. H., 1988. Liquidity and market structure. the Journal of Finance 43 (3), 617-633.

Hull, J., White, A., 1990. Pricing interest-rate-derivative securities. The Review of Financial Studies 3 (4), 573-592.

ISDA, 2016. Derivatives market analysis: Interest rate derivatives. a research note. International Swaps and Derivatives Association.

ISDA, 2017. ISDA Margin Survey September 2017. International Swaps and Derivatives Association.

Jones, C. K., 2001. A network model for foreign exchange arbitrage, hedging and speculation. International Journal of Theoretical and Applied Finance 4 (06), 837-852.

Krishnamurthy, A., 2010. Amplification mechanisms in liquidity crises. American Economic Journal: Macroeconomics 2 (3), 1-30.

Langfield, S., Liu, Z., Ota, T., 2014. Mapping the uk interbank system. Journal of Banking \& Finance 45, 288-303. 
Lee, S. H., 2013. Systemic liquidity shortages and interbank network structures. Journal of Financial Stability 9 (1), 1-12.

Li, D., Schürhoff, N., 2014. Dealer networks. Federal Reserve Board Staff Working Paper No. 2014-95.

Lin, L., Surti, J., 2015. Capital requirements for over-the-counter derivatives central counterparties. Journal of Banking \& Finance 52, 140-155.

Loon, Y. C., Zhong, Z. K., 2014. The impact of central clearing on counterparty risk, liquidity, and trading: Evidence from the credit default swap market. Journal of Financial Economics 112 (1), $91-115$.

Lopez-Espinosa, G., Rubia, A., Valderrama, L., Antn, M., 2013. Good for one, bad for all: Determinants of individual versus systemic risk. Journal of Financial Stability 9 (3), $287-299$.

Markose, S., Giansante, S., Shaghaghi, A. R., 2012. too interconnected to failfinancial network of us cds market: Topological fragility and systemic risk. Journal of Economic Behavior \& Organization 83 (3), 627-646.

Martinez-Jaramillo, S., Alexandrova-Kabadjova, B., Bravo-Benitez, B., SolrzanoMargain, J. P., 2014. An empirical study of the mexican banking systems network and its implications for systemic risk. Journal of Economic Dynamics and Control 40, $242-265$.

Murphy, D., Vasios, M., Vause, N., 2014. An investigation into the procyclicality of riskbased initial margin models. Bank of England Staff Working Paper No. 597.

Murphy, D., Vasios, M., Vause, N., 2016. A comparative analysis of tools to limit the procyclicality of initial margin requirements. Bank of England Staff Working Paper No. 597.

Newman, M., 2010. Networks: an introduction. 2010. United Slates: Oxford University Press Inc., New York.

Shleifer, A., Vishny, R., 2011. Fire sales in finance and macroeconomics. The Journal of Economic Perspectives 25 (1), 29-48.

Smith, D. J., 2011. Duration and convexity. Bond Math: The Theory behind the Formulas, 107-135.

Tasca, P., Battiston, S., 2016. Market procyclicality and systemic risk. Quantitative Finance 16 (8), 1219-1235.

van den End, J. W., Tabbae, M., 2012. When liquidity risk becomes a systemic issue: Empirical evidence of bank behaviour. Journal of Financial Stability 8 (2), 107 - 120.

Yellen, J., 2013. Interconnectedness and systemic risk: Lessons from the financial crisis and policy implications. Board of Governors of the Federal Reserve System, Washington, DC. 


\section{Tables and Figures}

\begin{tabular}{lll}
\hline Parameters & Description & Baseline Values \\
\hline$N$ & Number of banks & 245 \\
$N^{\text {CoreB }}$ & Number of core banks in the interbank layer & 16 \\
$N^{\text {Core } D}$ & Number of core banks in the OTC derivatives layer & 9 \\
$A_{i}^{B}$ & Interbank assets of bank $i$ & $\approx U(0.1 \%, 10 \%)$ of total assets \\
$A_{i}^{H L}$ & High-quality liquid assets of bank $i$ & $\approx U(1 \%, 5 \%)$ of total assets \\
$A_{i}^{L L}$ & Low-quality liquid assets of bank $i$ & $\approx U(10 \%, 30 \%)$ of total assets \\
$A_{i}^{O}$ & Other assets of bank $i$ & Residual \\
$L_{i}^{B}$ & Interbank liabilities of bank $i$ & Endogenous \\
$L_{i}^{O}$ & Other liabilities of bank $i$ & Residual \\
$K_{i}$ & Capital of bank $i$ & $\approx U(7 \%, 15 \%)$ of total assets \\
$\rho^{C C}$ & Probability of core-to-core connection & 0.65 \\
$\rho^{C P}$ & Probability of core-to-periphery connection & 0.15 \\
$\rho^{P P}$ & Probability of periphery-to-periphery connection & 0.00 \\
$\Delta R_{m}$ & Change in market interest rate in basis points & 60 \\
$\omega$ & Central clearing percentage & $72 \%$ \\
$\beta$ & Measure of modified duration & 2 \\
$\lambda$ & Liquidity hoarding multiplier & 1 \\
$\gamma$ & Liquidity hoarding cost & $\approx U(0 \%, 5 \%)$ \\
$\alpha$ & System-wide haircut & $10 \%$ \\
$\alpha_{i}$ & Bank-specific haircut & $\approx U(0 \%, 5 \%)$ \\
\hline
\end{tabular}

Table 1: Description of parameters and their initial values that are used in the baseline simulation. The values of some parameters are determined endogenously during each run. 


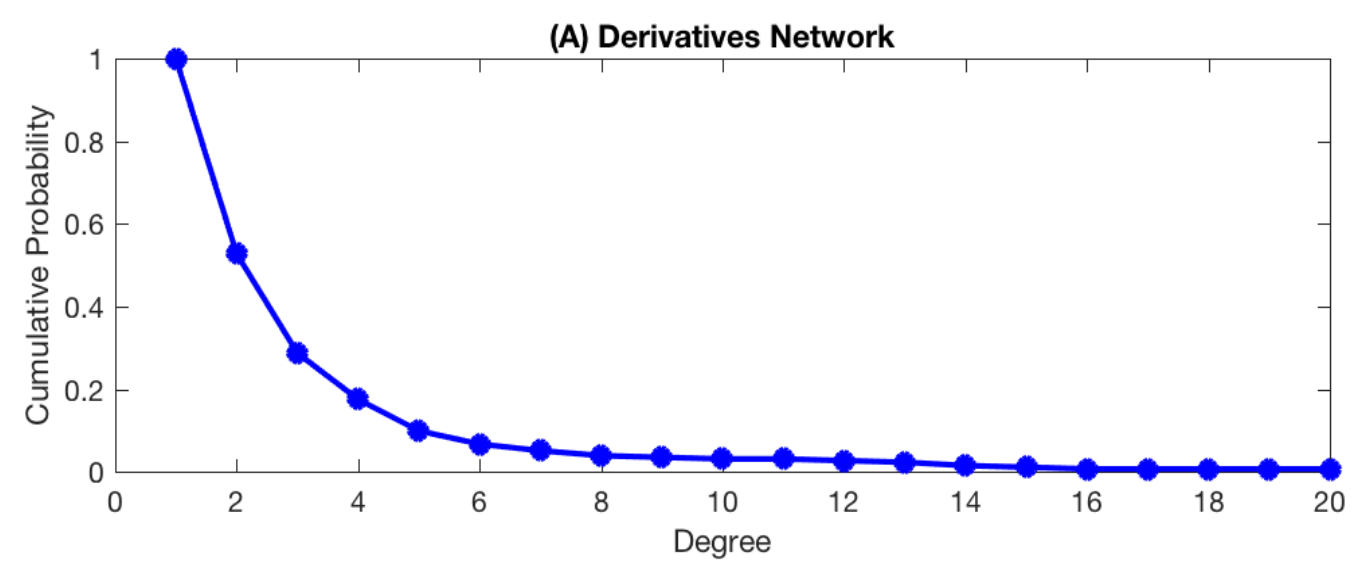

(B) Interbank Network

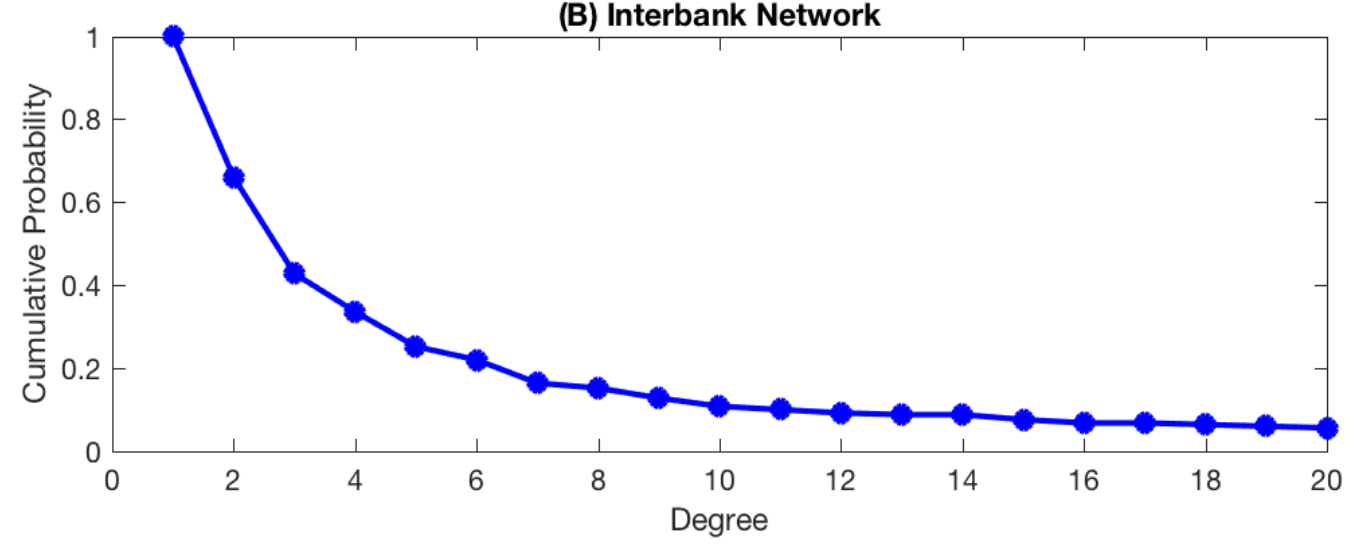

Fig. 1: Degree distribution of both the derivatives and the interbank layers of the market network. The figure shows the cumulative density function $(\mathrm{CDF})$ of the degree distribution based on the average of 100 simulations.

\begin{tabular}{l|l|l}
$\mathbf{t}=\mathbf{0}$ & $\mathbf{t}=\mathbf{1}$ & $\mathbf{t}=\mathbf{2}$ \\
\hline Set up banks' balance sheets & Trading Strategies & Margin Calls \\
Set up interbank network & Trading and Clearing & $\begin{array}{l}\text { Spillover Contagion } \\
\text { Systemic Risk }\end{array}$
\end{tabular}

Fig. 2: Simulation Framework 


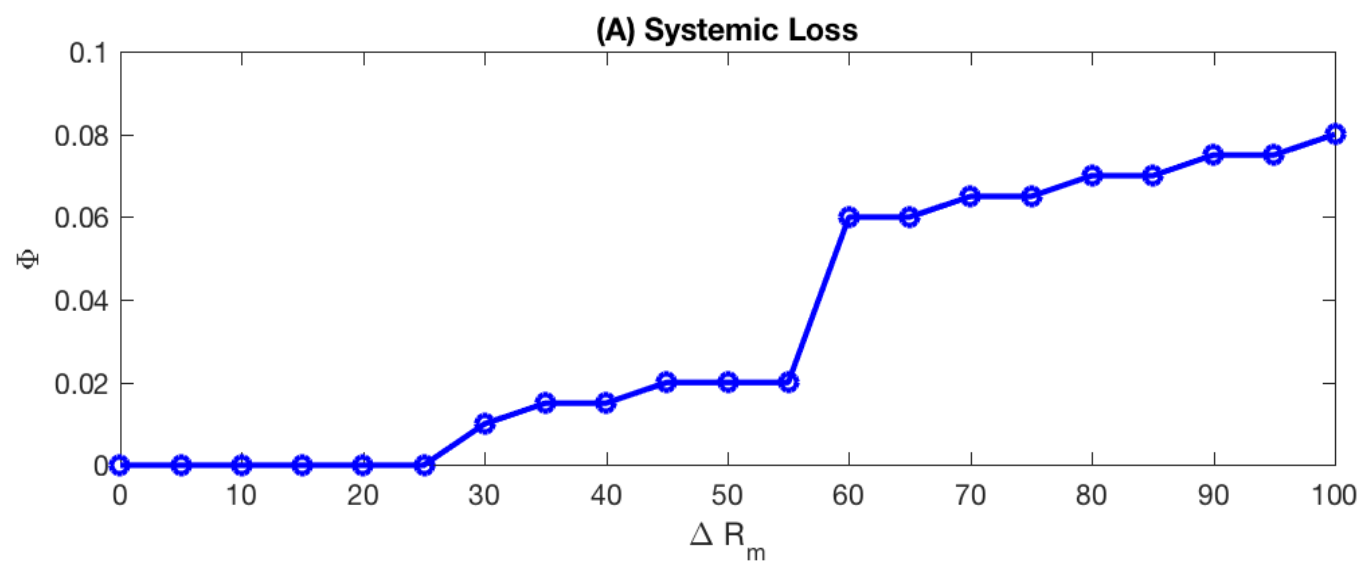

(B) Number of Distressed Banks

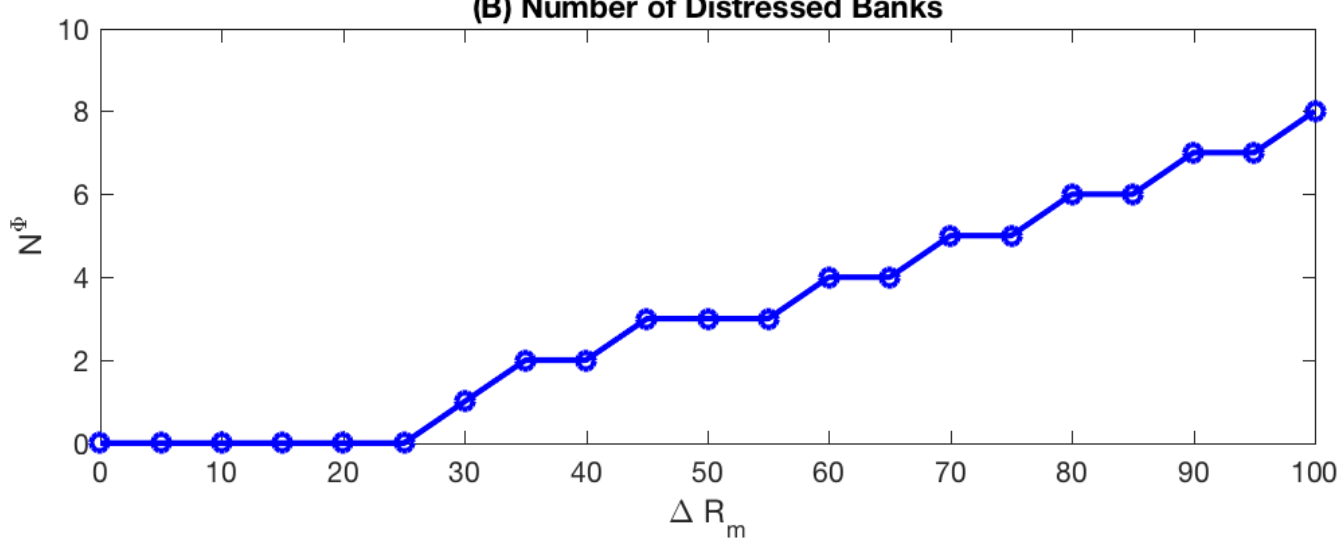

Fig. 3: Stylized Systemic Liquidity Crisis. The simulation runs using parameters in Table 1. $\Phi$ is the systemic loss due to liquidity hoarding, $N^{\Phi}$ is the number of distressed banks and $\Delta R_{m}$ is the basis point change in the benchmark market interest rate. The result is based on the average of 100 simulations. 


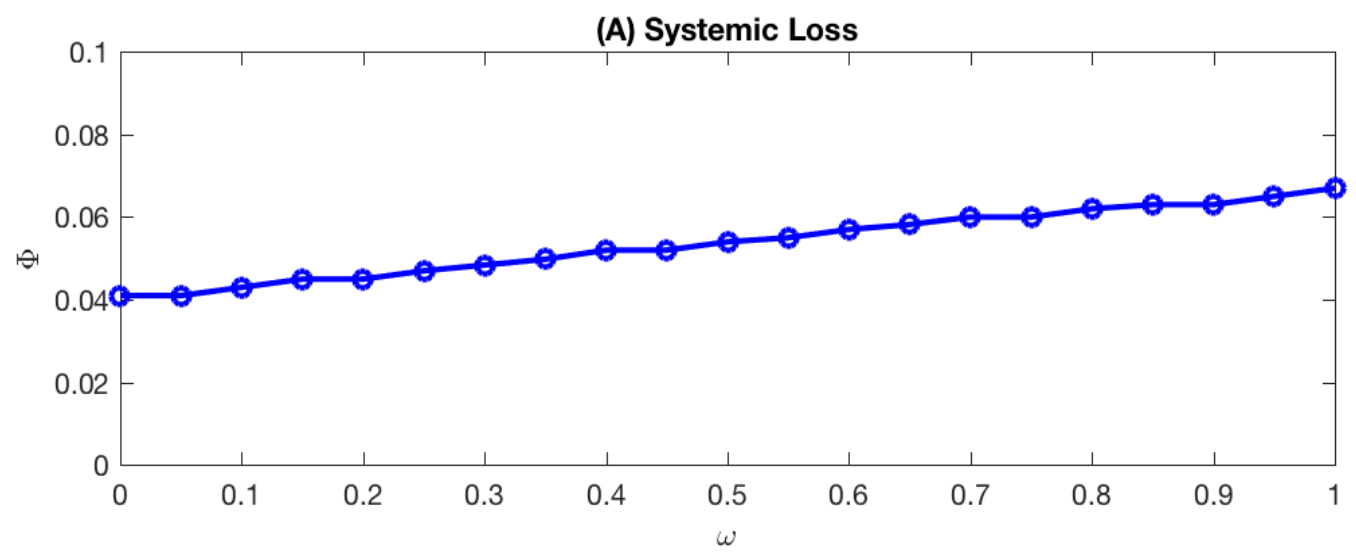

(B) Number of Distressed Banks

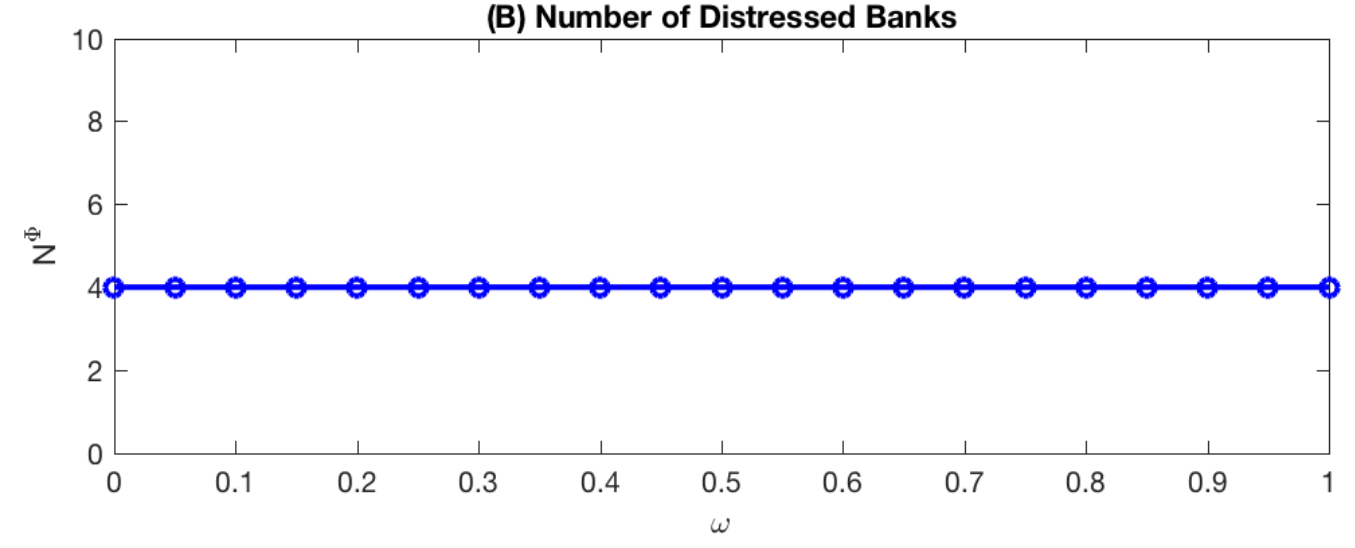

Fig. 4: Impact of central clearing on systemic liquidity risk. The simulation runs using parameters in Table 1 with varying central clearing percentage values. $\Phi$ is the systemic loss due to liquidity hoarding, $N^{\Phi}$ is the number of distressed banks and $\omega$ is the percentage of central clearing. The result is based on the average of 100 simulations. 


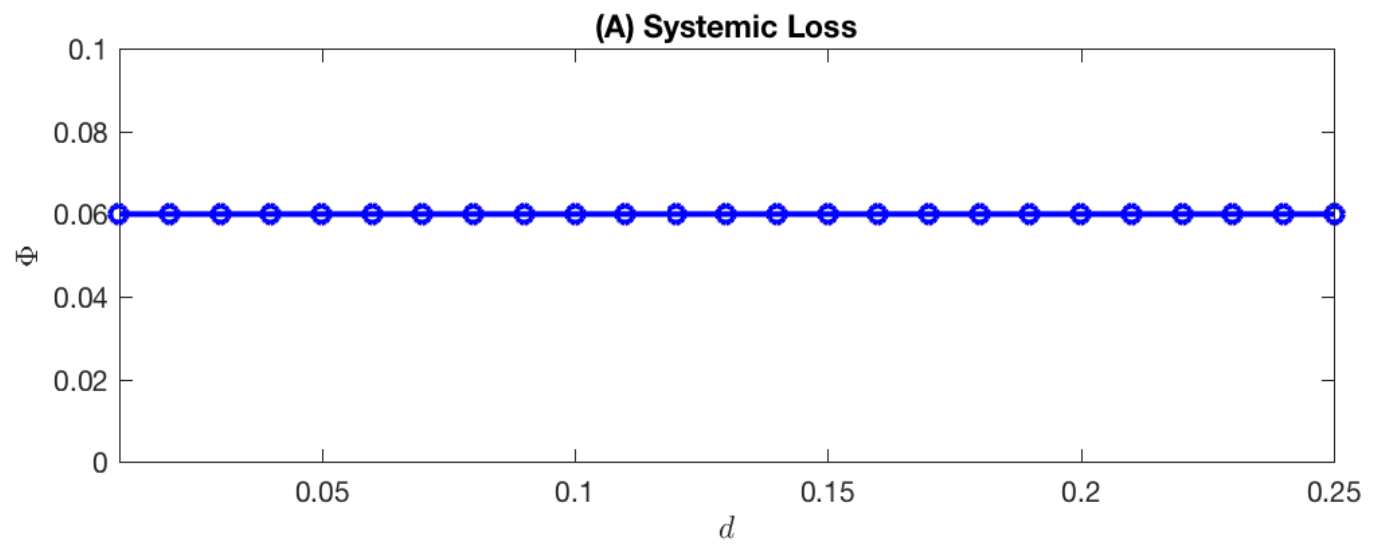

(B) Number of Distressed Banks

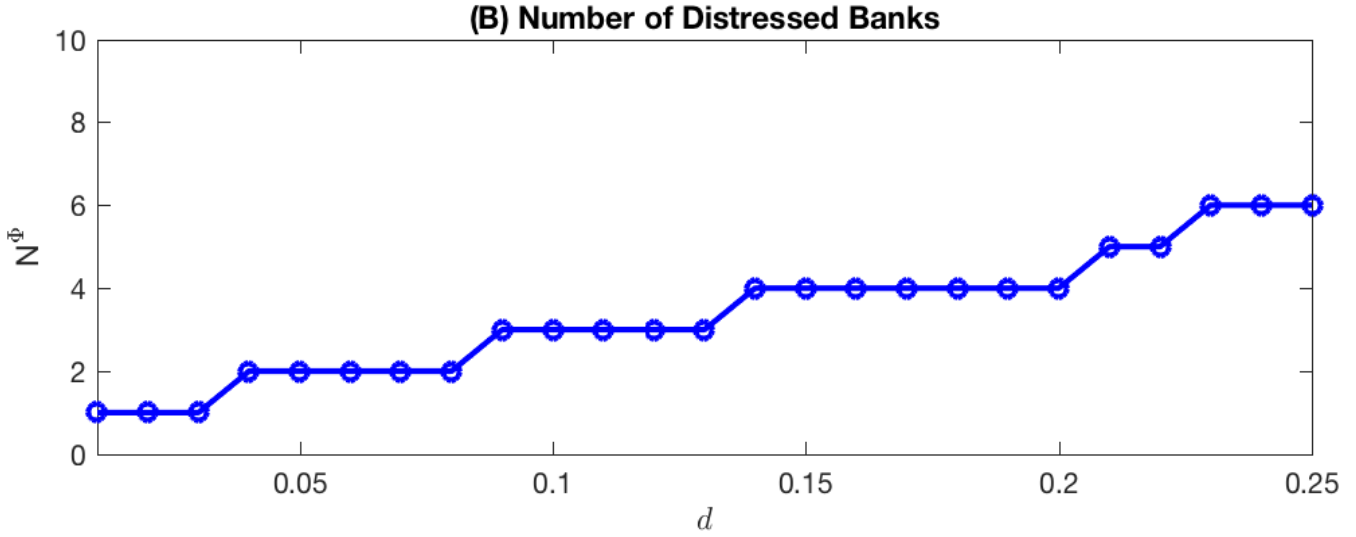

Fig. 5: Impact of interconnectedness on systemic liquidity risk. The simulation runs using parameters in Table 1 with varying network density values. $\Phi$ is the systemic loss due to liquidity hoarding, $N^{\Phi}$ is the number of distressed banks and $d$ is density. The result is based on the average of 100 simulations. 


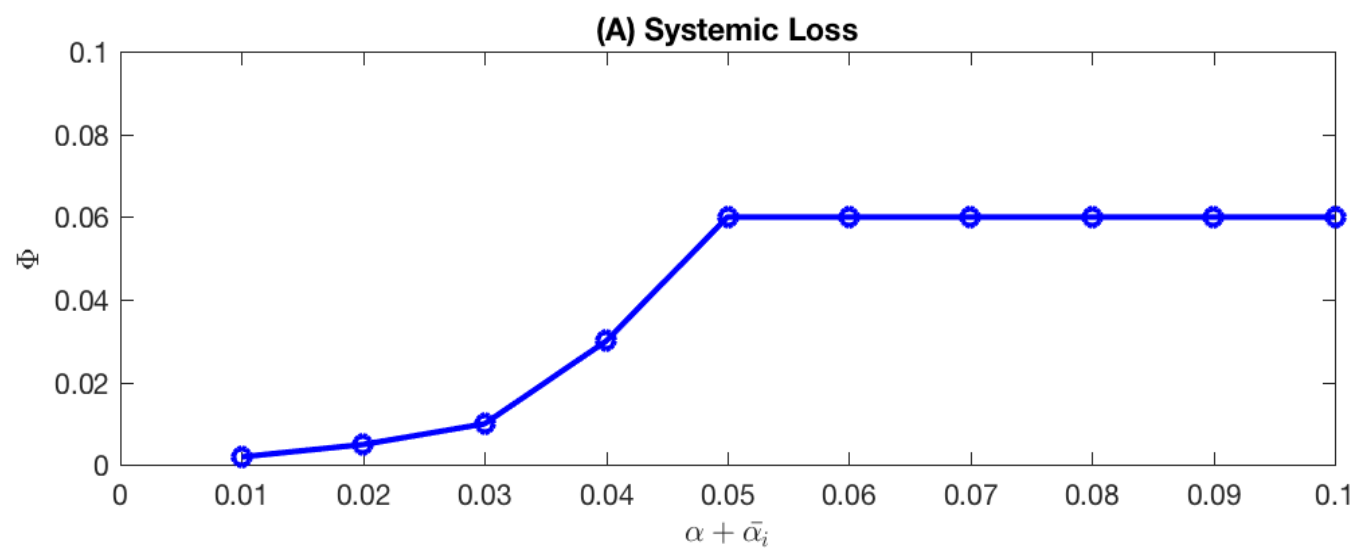

(B) Number of Distressed Banks

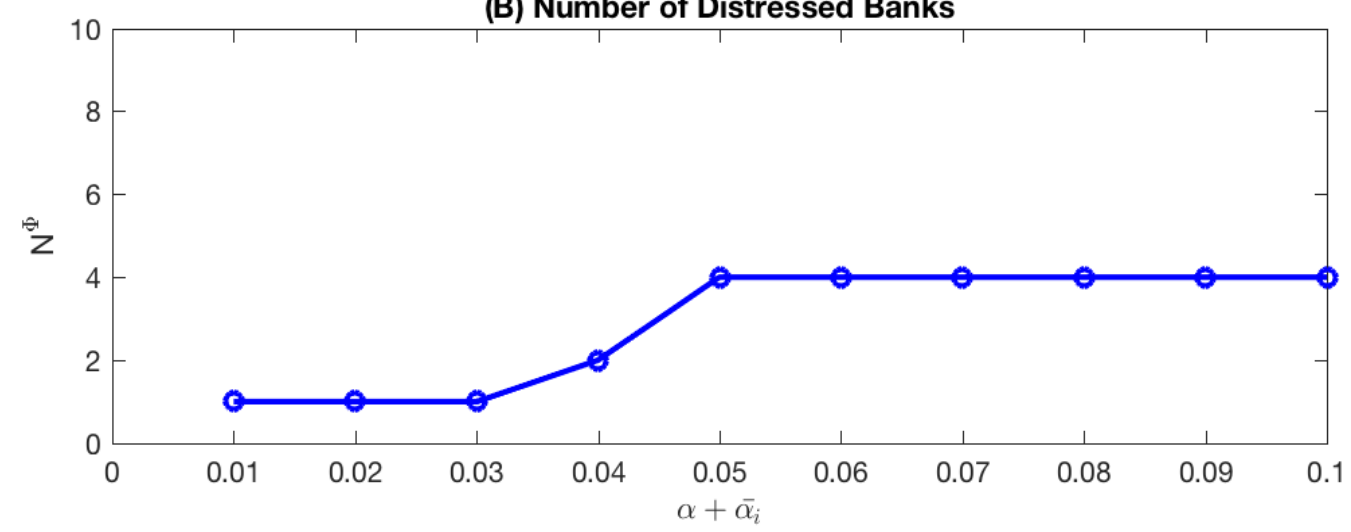

Fig. 6: Impact of haircut on systemic liquidity risk. The simulation runs using parameters in Table 1 with varying haircut values. $\Phi$ is the systemic loss due to liquidity hoarding, $N^{\Phi}$ is the number of distressed banks and $\alpha+\overline{\alpha_{i}}$ is the total haircut. The result is based on the average of 100 simulations. 


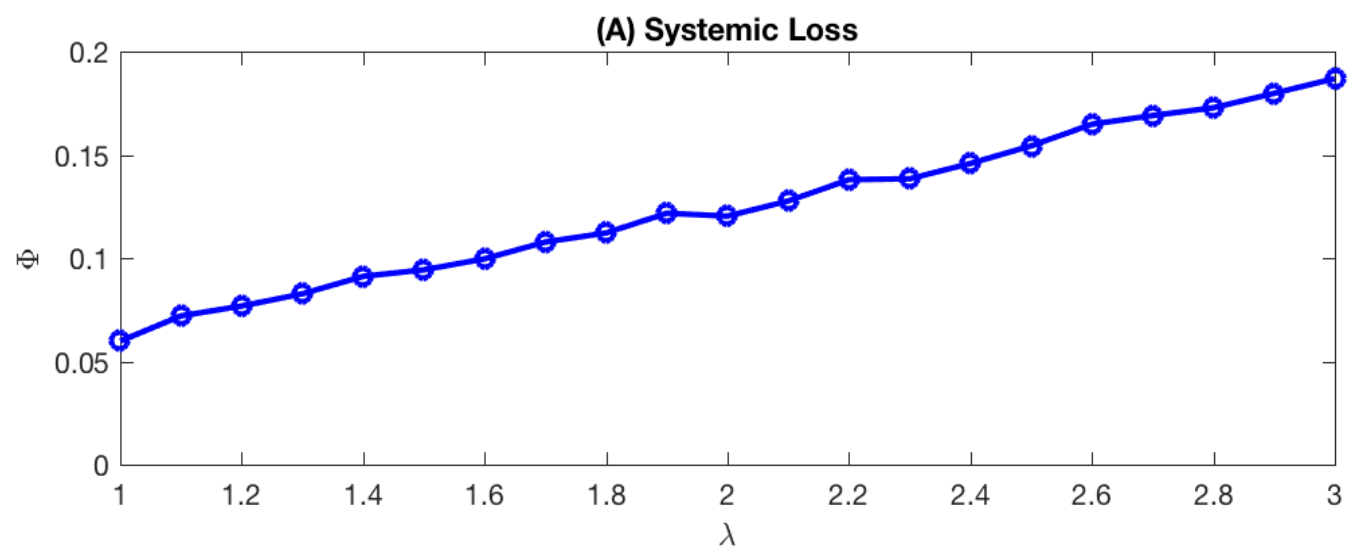

(B) Number of Distressed Banks

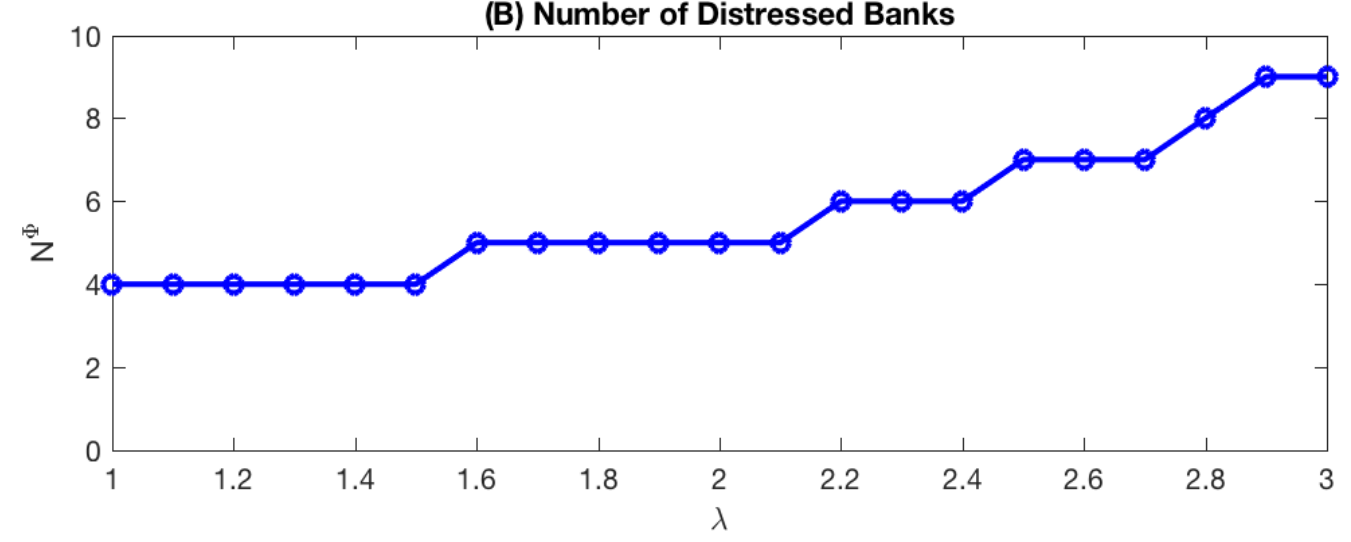

Fig. 7: Sensitivity analysis of the liquidity hoarding multiplier.The simulation runs using parameters in Table 1 with varying liquidity hoarding multiplier values. $\Phi$ is the systemic loss due to liquidity hoarding, $N^{\Phi}$ is the number of distressed banks and $\lambda$ is the liquidity hoarding multiplier. The result is based on the average of 100 simulations. 


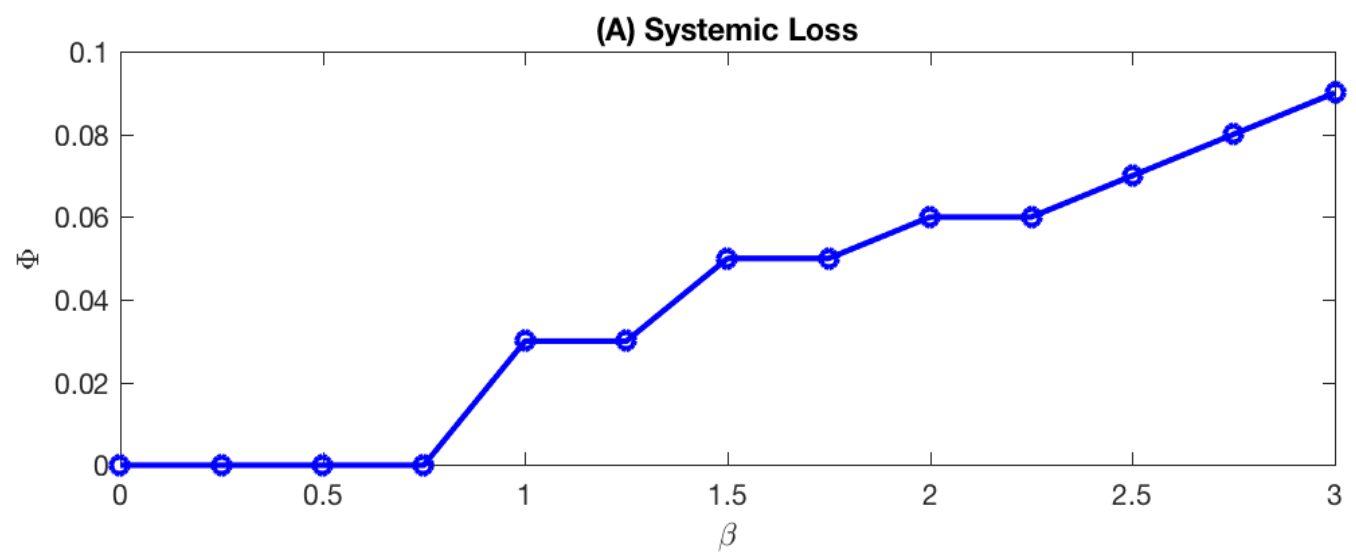

(B) Number of Distressed Banks

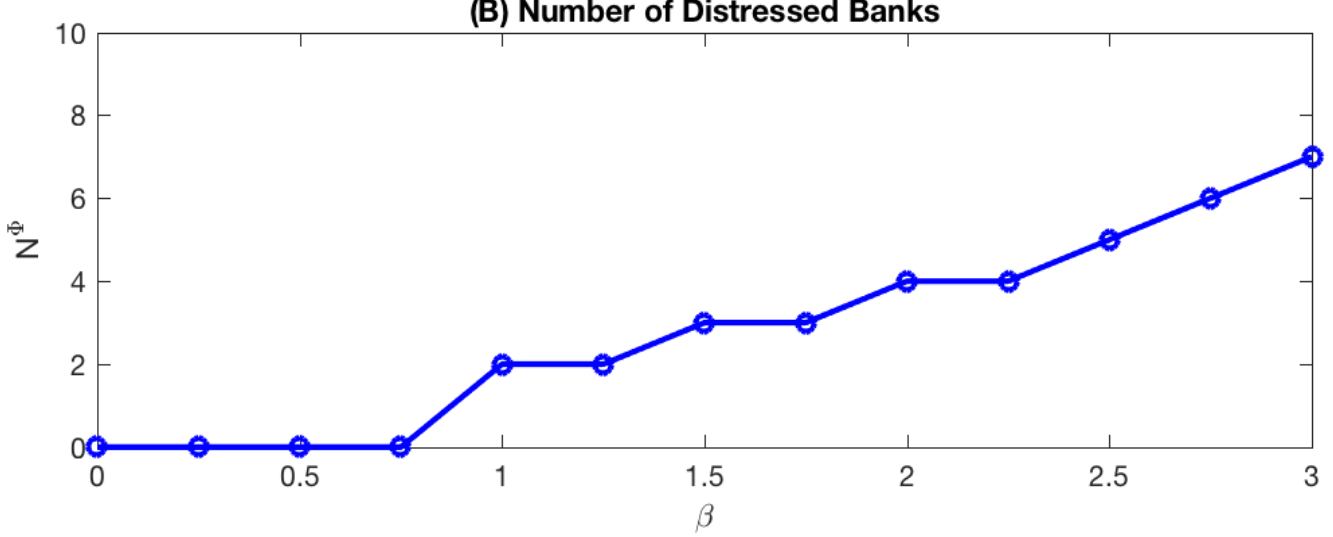

Fig. 8: Sensitivity analysis of the derivatives contract value sensitivity to changes in market interest rates. The simulation runs using parameters in Table 1 with varying modified duration values. $\Phi$ is the systemic loss due to liquidity hoarding, $N^{\Phi}$ is the number of distressed banks and $\beta$ is the measure of modified duration. The result is based on the average of 100 simulations. 